\title{
Numerical optimization of absorber and CdS buffer layers in CIGS solar cells using SCAPS
}

\author{
Tariq AlZoubi ${ }^{1}$ and Mohamed Moustafa ${ }^{2}$ \\ ${ }^{1}$ College of Engineering and Technology, American University of the Middle East, Egaila, Kuwait \\ ${ }^{2}$ Department of Physics, School of Sciences and Engineering, The American University in Cairo, New Cairo, 11835, Egypt
}

\begin{abstract}
In this study, numerical optimization and analysis utilizing SCAPS-1D software package of CIGS solar cell structure are presented. The electrical properties and the photovoltaic performance parameters of CIGS thin film solar cells with Molybdenum as a back contact have been investigated. The possible effects of absorber CIGS and CdS buffer layers thickness, doping level and band gap energy on solar cell performance parameters are addressed. The conversion efficiency of the solar cell has been found to increase significantly with the doping concentration in the range from $10^{14}$ to $10^{18} \mathrm{~cm}^{-3}$ and absorber thickness ranging from $500 \mathrm{~nm}$ to $4000 \mathrm{~nm}$. An optimum conversion efficiency of $21.35 \%$ to $24.21 \%$ has been obtained with thinner absorber thicknesses ranging from $1500 \mathrm{~nm}$ to 2500 $\mathrm{nm}$ at band gap energy of $1.15 \mathrm{eV}$ and doping concentration of about $10^{17} \mathrm{~cm}^{-3}$. Moreover, the thickness of CdS buffer layer should be greater than $40 \mathrm{~nm}$ and less than $60 \mathrm{~nm}$ to maintain the remarkable overall solar cell performance. These results are very promising for future potential applications in thin and high performance CIGS solar cells technology.
\end{abstract}

Keywords: CIGS, solar cells, thin films, CdS, SCAPS

\section{Introduction}

Copper-indium-gallium-diselenide $\mathrm{CuIn}_{\mathrm{x}} \mathrm{Ga}_{1-\mathrm{x}} \mathrm{Se}_{\mathrm{x}}$ (CIGS) solar cells are considered among the prime candidates for future thin film solar cell devices. This is due to their potential characteristics such as high performance, high optical absorption coefficient in the visible spectrum of sunlight, excellent outdoor stability, tuneable band gap, low cost, outdoor long-term stability and their distinguished optoelectronics properties [2]. The highest laboratory reported efficiency for CIGS solar cell is about 20\% [3]. Whereas, efficiencies of about $17.5 \%$ for CIGS thin film sub-modules have been demonstrated [4]. In high efficiency CIGS solar cells, soda lime glass substrate and Molybdenum (Mo) back contacts have generally been used.

Several experimental and theoretical studies to improve the performance of the electrical and optical properties of CIGS solar cells were reported. For review of the different aspects of CIGS solar cells, the reader may refer to literatures [5-8]. Despite of these research efforts, further optimizations can be obtained to increase the device efficiency and to reduce the fabrication costs. Much attention has been paid recently to the preparation of very thin absorber layers in CIGS based solar cells [9-12]. The reduction of the absorber layer thickness has been found to play a key role in further improvement of CIGS solar cells technology. As a result, significant reduction of the consumption of expensive indium and gallium thereby their cost for large scale production is achieved. Another important layer in a heterojunction solar cell structure is the buffer layer. The role of a buffer layer is to form a junction with the absorber layer to maximize the amount of incoming light to the absorber layer. Accordingly, the buffer layer should have minimum absorption loss, very low surface recombination and electrical

*Manuscript received September 4, 2018; revised March 25, 2019.

Corresponding author. E-mail address: tariq.alzoubi@aum.edu.kw \& mohamed.orabi@ucegypt.edu

doi: 10.12720 /sgce.8.3.291-298 
resistance in order to achieve the maximum collection of photogenerated charge carrier at the back and front contacts. To satisfy such desired features, the buffer layer should be as thin as possible and should have wider band gap in comparison with the CIGS absorber layer.

Numerical models of solar cell devices have been used to reach a thorough and clear understanding of the underlying physics that control the device performance. Applying analytical models and numerical simulations can be utilized to explore the possible effects of different material parameters on the final solar cells characteristics. The findings of such numerical studies and analysis can be used later on to improve their performances. In this paper, we report on a quantitative numerical study, using Solar Cell Capacitance Simulator in one dimension (SCAPS-1D), of the effects of thinning the CIGS layer by numerical analysis. We initiate the work with the study of the band gap energy optimization of the absorber layer, followed by thinning CIGS absorber layer thickness. After that, a study and optimization of buffer layer was conducted taking into consideration the possible experimental applications and limitations.

\section{Device Simulation and Modelling}

The structure of CIGS cells is a heterojunction, which is formed of different semiconductor materials. A typical CIGS thin film solar cell structure consists of a p-type wide band gap absorber layer (CIGS) of thickness ranging from $500 \mathrm{~nm}$ to $4000 \mathrm{~nm}$ with an n-type CdS as buffer layer with thickness ranging from $30 \mathrm{~nm}$ to $210 \mathrm{~nm}$, and $200 \mathrm{~nm} \mathrm{ZnO}$ as window layer. The structure is deposited on Mo as back contact coated back glass substrate. Fig. 1 depicts the schematic diagram of the CIGS solar cell. In this analytical model, SCAPS-1D is used to investigate the effects of CIGS layer thickness and CdS buffer layer in CIGS-based solar cell. SCAPS is a software developed at University of Gent [13]. It is widely used for the simulation of different types of solar cells, e.g. CIGS and CdTe based solar cells [14]. SCAPS calculates the steady-state band diagram, recombination profile, and carrier transport in one dimension, based on Poisson equation together with hole and electron continuity equations [15].

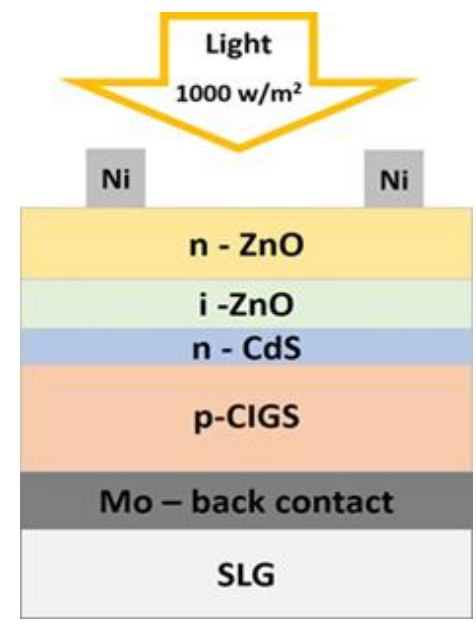

Fig. 1. The layers scheme of a typical CIGS solar cell with CdS buffer layer based on Mo back contact.

The proposed CIGS structure has been modeled under an AM 1.5 light spectrum with $1000 \mathrm{~W} / \mathrm{m}^{2}$ light intensity. Incorporating various material parameters into SCAPS-1D for several analysis aspects, solar cell performance parameters such as open-circuit voltage $\left(\mathrm{V}_{\mathrm{oc}}\right)$, short circuit current density $\left(\mathrm{J}_{\mathrm{sc}}\right)$, fil factor (FF), and conversion efficiency can be investigated. The various physical parameters used in the simulation are summarized in Table 1 from Refs. [16-18]. All obtained results in this study have been simulated using Mo and $\mathrm{Ni}$ as back and front contacts, respectively. 
Table 1. Material properties applied in the numerical analysis for CIGS-based solar cell at $300 \mathrm{~K}$ for both CdS buffer and CIGS absorber layers.

\begin{tabular}{lllll}
\hline Parameter & CIGS & CdS & i-ZnO & ZnO \\
\hline Thickness $(\mu \mathrm{m})$ & $0.5-4$ & $0.03-0.240$ & 0.05 & 0.15 \\
$\varepsilon_{r}$ & 13.6 & 9 & 9 & 9 \\
$\mu_{n}\left(\mathrm{~cm}^{2} / V s\right)$ & 300 & 10 & 200 & 200 \\
$\mu_{p}\left(\mathrm{~cm}^{2} / V s\right)$ & 30 & 1 & 25 & 25 \\
$N_{A}\left(\mathrm{~cm}^{-3}\right)$ & $10^{12}-10^{18}$ & 0 & 0 & 0 \\
$N_{D}\left(\mathrm{~cm}^{-3}\right)$ & 0 & $10^{12}-10^{18}$ & 1 & $5 \times 10^{17}$ \\
$E_{g}\left(\mathrm{eVV}^{-3}\right.$ & $1.1-1.5$ & 2.40 & 3.3 & 3.3 \\
$N_{c}\left(\mathrm{~cm}^{-3}\right)$ & $2.2 \times 10^{18}$ & $2.2 \times 10^{18}$ & $2.2 \times 10^{18}$ & $2.2 \times 10^{18}$ \\
$N_{v}\left(\mathrm{~cm}^{-3}\right)$ & $1.9 \times 10^{19}$ & $1.8 \times 10^{19}$ & $1.8 \times 10^{19}$ & $1.8 \times 10^{19}$ \\
$v_{t-h}(\mathrm{~cm} / \mathrm{s})$ & $1 \times 10^{7}$ & $1 \times 10^{7}$ & $1 \times 10^{7}$ & $1 \times 10^{7}$ \\
$v_{t-e}(\mathrm{~cm} / \mathrm{s})$ & $1 \times 10^{7}$ & $1 \times 10^{7}$ & $1 \times 10^{7}$ & $1 \times 10^{7}$ \\
$\chi(\mathrm{eV})$ & 4.4 & 4.2 & 4.6 & 4.6 \\
\hline
\end{tabular}

\section{Results and Discussion}

\subsection{Modelling and optimization of absorber bandgap energy}

One key advantage of using CIGS as absorber is its tunable band gap energy over a wide range starting from $1 \mathrm{eV}$ to $1.7 \mathrm{eV}$, which extremely depends on the ratio of indium and gallium concentration in the film as described by equation 1 . The modeling and optimization of absorber band gap energy are vital and essential. Undoubtedly the variation of absorbers band gap energy does affect the solar cell performance. Experimental studies show that the optimum range of CIGS band gap to have high conversion efficiency is from $1.12 \mathrm{eV}$ to $1.26 \mathrm{eV}$ [19]. Recently, a successful effort has been done to improve the energy conversion efficiency of CIGS solar cells with band gaps up to $1.45 \mathrm{eV}$ [20]. In this study, the energy bandgap values of the absorber layer have been varied in the range from $1.1 \mathrm{eV}$ to $1.5 \mathrm{eV}$. Fig. 2 depicts the obtained simulated results of the solar efficiency as a function of the bandgap energy with different CIGS thicknesses ranging from $500 \mathrm{~nm}$ to $4000 \mathrm{~nm}$. It can be observed that, for different CIGS layer thickness the peak of the conversion efficiency is centered at bandgap energy value of $1.15 \mathrm{eV}$.

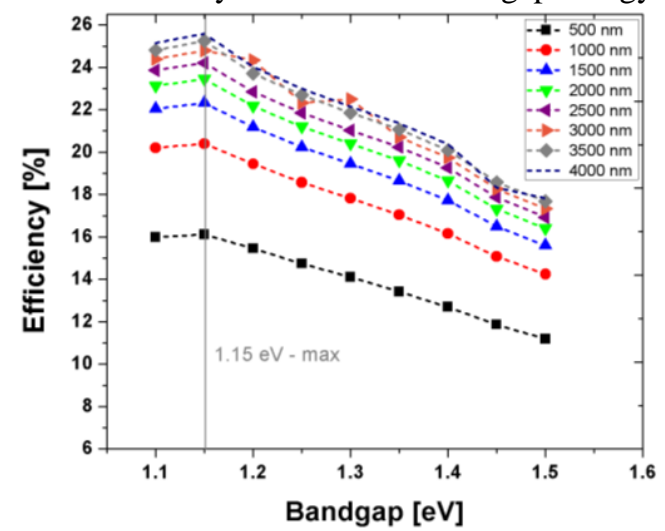

Fig. 2. Solar cell conversion efficiency as a function of CIGS-absorber bandgap energy at different CIGS thicknesses ranging from $500 \mathrm{~nm}$ to $4000 \mathrm{~nm}$.

Varying the bandgap due to the change in the indium (In) contents in $\mathrm{CuIn}_{\mathrm{x}} \mathrm{Ga}_{(1-\mathrm{x})} \operatorname{Se}_{\mathrm{x}}$ (CIGS) layer. The bandgap energy of the absorber of $1.15 \mathrm{eV}$ corresponds to In concentration of $(x=30 \%)$ as described by equation 1 .

$E_{g}=1.02+0.67 x+b x(x-1)$ 
Where $x$ represents the proportion of gallium in the absorber i.e. the ratio of $\mathrm{Ga} /(\mathrm{Ga}+\mathrm{In})$ ranging from $x=0$ to $x=1, \mathrm{~b}$ is the optical bowing coefficient reported with values ranging from 0.11 to 0.2 [21-23]. Therefore, increasing the bandgap energy above $1.15 \mathrm{eV}$ promotes structural defects formation at the interface as well as inside the absorber volume. This can be attributed to the high lattice-mismatched strain stored inside the absorber layer, which is released as structural defects formation leading to lower optical absorption that degrades the overall solar cell performance [24-26].

\subsection{Modelling and optimization of CIGS absorber thickness and doping level}

The CIGS absorber thickness and acceptor carrier concentration $\left(\mathrm{N}_{\mathrm{A}}\right)$ have been numerically investigated in the ranges of 500 to $4000 \mathrm{~nm}$ and $10^{12}$ to $10^{18} \mathrm{~cm}^{-3}$, respectively. The main aim of this study is to obtain thinner CIGS layer with almost no or very small losses in cell efficiency and performance. As a result, a cost reduction can be achieved by reducing the amount of the expensive used materials such as Gallium and Indium in CIGS-based solar cells.
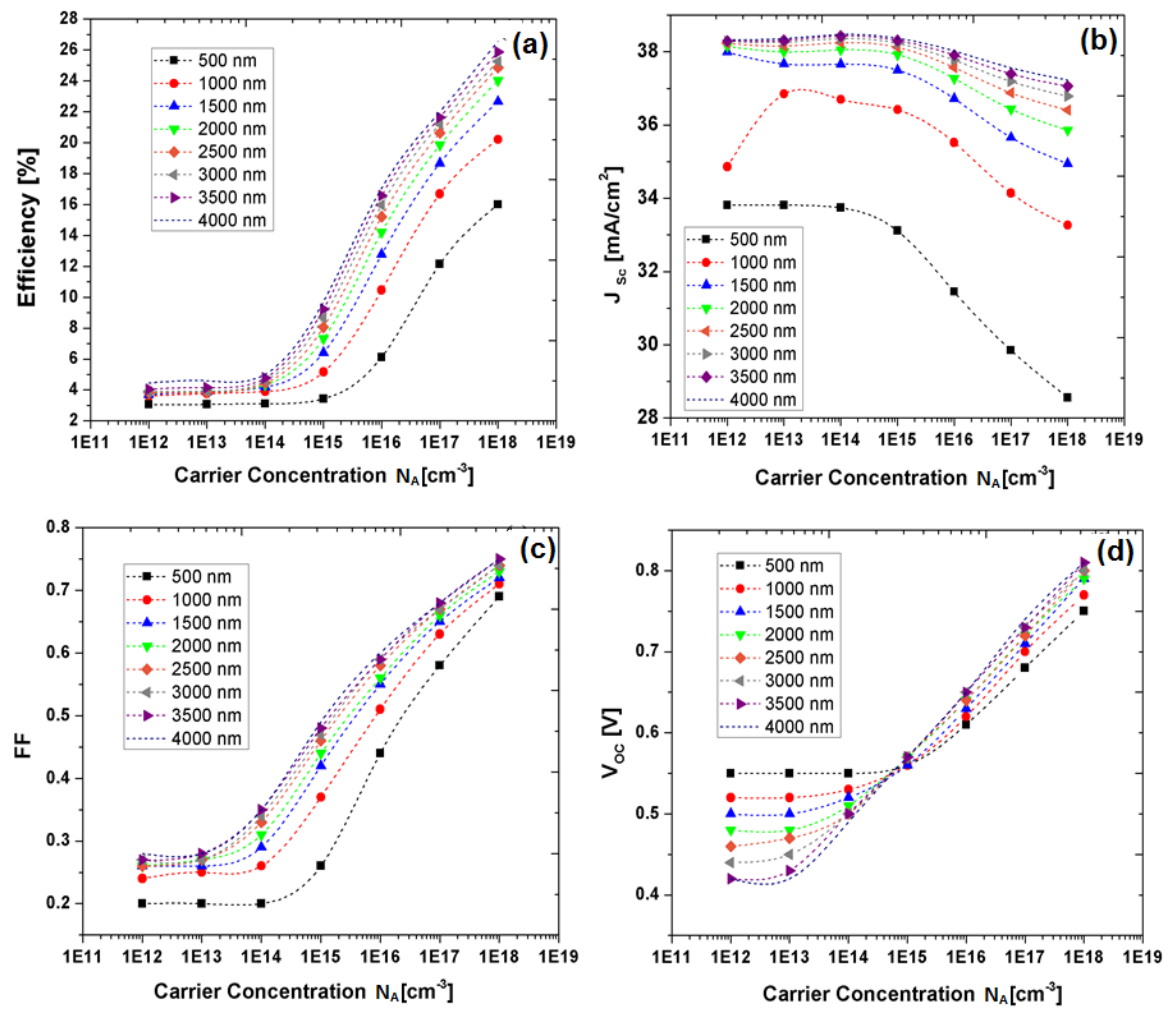

Fig. 3. The simulated electrical performance parameters as a function of the acceptor charge carrier concentration $\left(\mathrm{N}_{\mathrm{A}}\right)$ : (a) Conversion efficiency, (b) short-circuit current density (Jsc), (c) Filling factor (FF), (d) open-circuit voltage $\left(\mathrm{V}_{\mathrm{oc}}\right)$ at different CIGS absorber thicknesses ranging from $500 \mathrm{~nm}$ to $4000 \mathrm{~nm}$.

However, the absorber thickness is still considered as one of the key challenges in today large-scale and massive production CIGS solar cells industry. Fig. 3 (a to d) shows the electrical performance parameters as a function of holes concentration $\left(\mathrm{N}_{\mathrm{A}}\right)$ (log-scale) at different CIGS absorber thicknesses.

Fig. 3 (a) shows that low hole doping level $\left(<10^{15} \mathrm{~cm}^{-3}\right)$ results in a dramatic drop of device conversion efficiency with values less than $8 \%$. On the other hand, small cell efficiency variations were detected with the increase of CIGS absorber thicknesses at this doping level. Short circuit current density $\left(\mathrm{J}_{\mathrm{sc}}\right)$ in the cell is observed to have a value of about $38 \mathrm{~mA} / \mathrm{m}^{2}$ at absorber thicknesses ranging from 1500 
$\mathrm{nm}$ to $4000 \mathrm{~nm}$ (see Fig. 3b). For absorber thicknesses below $1000 \mathrm{~nm}$, a significant decrease of $\mathbf{J}_{\mathrm{sc}}$ values was observed with the increase of the doping level. On the other hand, open-circuit voltage $\left(\mathrm{V}_{\mathrm{oc}}\right)$ shows a linear increase with carrier concentrations above $10^{15} \mathrm{~cm}^{-3}$ (Fig. 3d). Additionally, the fill factor (FF) shows similar behavior with the increase of the doping concentration in the same range (Fig. 3c). Based on equation 2, the combined effect of current density $\mathbf{J}_{\mathrm{sc}}$ saturation (Fig. 3b) together with the rapid increase of the $\mathrm{V}_{\mathrm{oc}}$ and FF (Fig.3 c-d) as a function of acceptor concentration explain the enhanced efficiency in the simulated results.

$$
\eta=\frac{V_{O C} F F J_{S C}}{P_{i n}}
$$

The impact of CIGS absorber thickness variations on solar cell basic properties was extensively investigated. Fig. 4a shows the spectral response of the device as a function of CIGS absorber thickness. The simulated results reveal the significant increase of the quantum efficiency (QE) with the increase of absorber thickness in the range of $500 \mathrm{~nm}$ to $4000 \mathrm{~nm}$. Using this model, Enhanced quantum efficiency of about $90 \%$ at reduced CIGS absorber thicknesses ranging from 1500 to $2500 \mathrm{~nm}$ has been maintained. This can be ascribed to the increase of photons collection at longer wavelengths. The absorption of longer wavelengths photons has resulted in generation of more electron-hole pairs in the device, leading to an increase in current density $\left(\mathrm{J}_{\mathrm{sc}}\right)$ at thicker absorber layers (Fig. 4b). Additional reduction in CIGS thickness below $1000 \mathrm{~nm}$ results in more optical losses, which might be caused by the surface recombination at the back contact. The recombination of the charge carriers at the back contact is due to the close position of the depletion region, which becomes very near to back-contact at very thin absorber thicknesses.
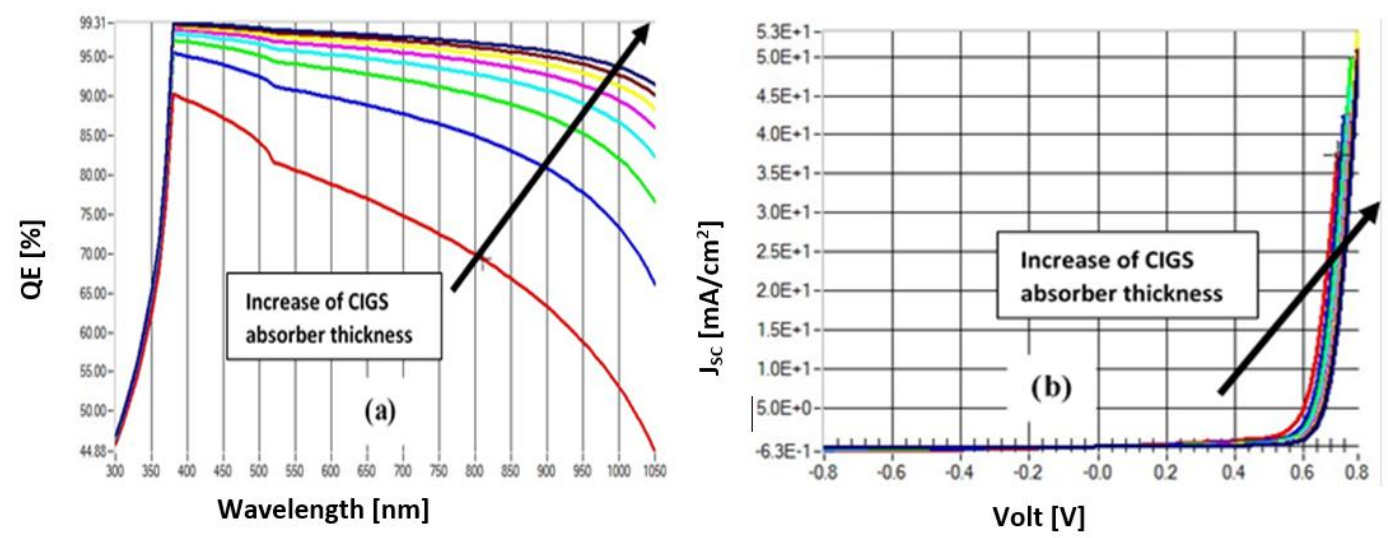

Fig. 4. (a) Spectral response of the enhanced quantum efficiency (QE) at longer wavelength with the increase of absorber thickness. (a) Short-circuit current density (Jsc) as a function of CIGS absorber thickness.

\subsection{Modelling and optimization of CdS buffer layer thickness and doping level}

One of the main targets of this simulation is to reduce all optical and electrical losses caused by the buffer layer. Therefore, the thicknesses and doping level of CdS layer were varied in the ranges of $30 \mathrm{~nm}$ to $210 \mathrm{~nm}$ and $10^{12}-10^{18} \mathrm{~cm}^{-3}$, respectively. Fig. 5 depicts the influence of CdS buffer on the CIGS performance parameters. The simulated results suggest that no change of all performance parameters with doping of buffer up to donor concentration $\left(\mathrm{N}_{\mathrm{D}}\right)$ of $10^{15} \mathrm{~cm}^{-3}$. However, a further increase in doping level has resulted in an overall CIGS efficiency improvement by $4 \%$ at a higher donor concentration of $10^{18}$ $\mathrm{cm}^{-3}$. 

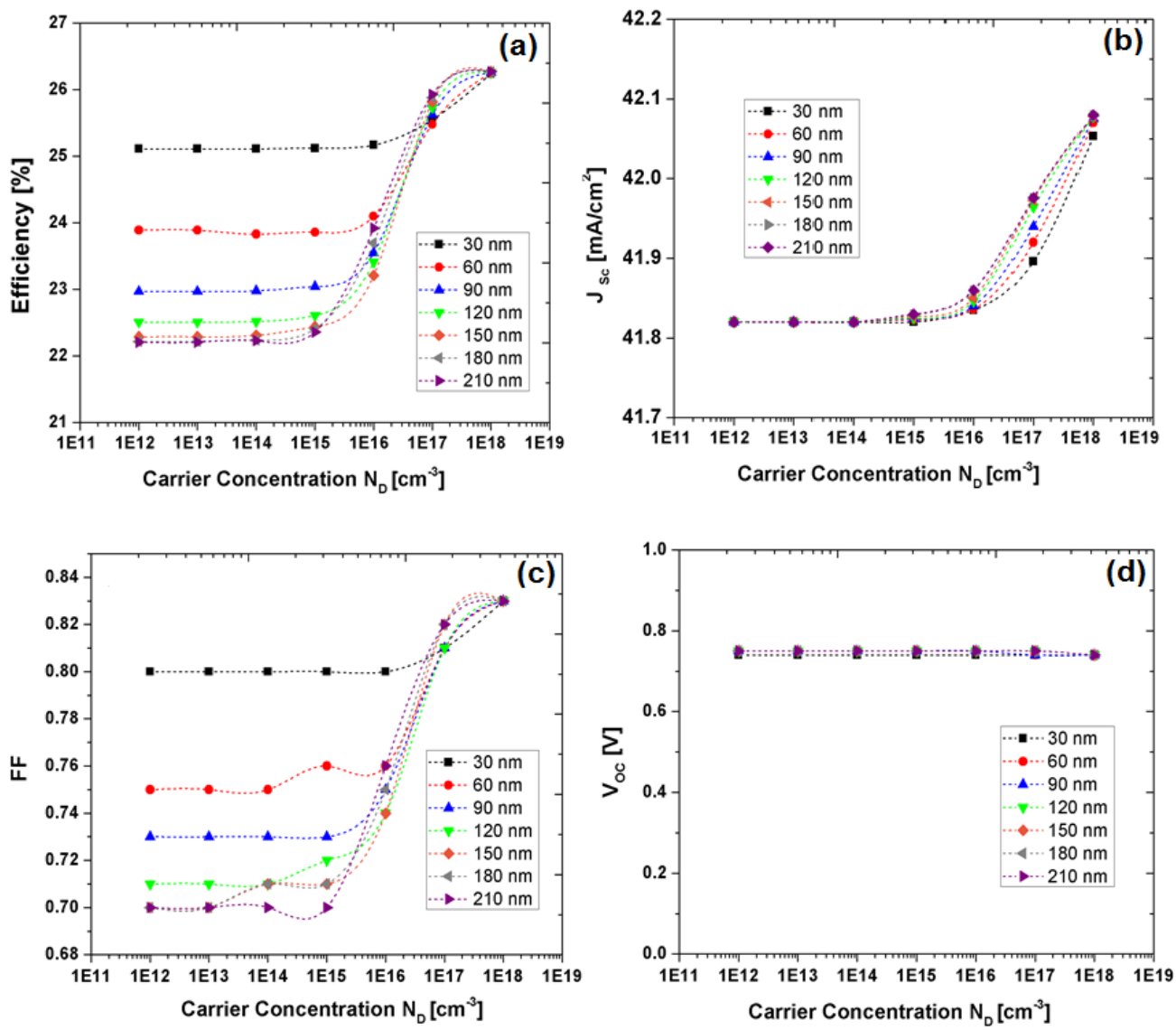

Fig. 5. The simulated electrical performance parameters as a function of donor charge carrier concentration $\left(\mathrm{N}_{\mathrm{D}}\right)$ : $(\mathrm{a})$ Conversion efficiency, (b) short-circuit current density (Jsc), (c) Filling factor (FF), (d) open-circuit voltage (Voc) at different CdS buffer thicknesses $(30-210) \mathrm{nm}$.

However, it is desirable to keep the buffer layer as thin as possible with very high doping level to maintain the remarkable overall CIGS-Based solar cells performance. The optimum buffer thickness must be in the range of $40-60 \mathrm{~nm}$ with doping level of about $10^{18} \mathrm{~cm}^{3}$ due to experimental limitations of CdS thicknesses below than $40 \mathrm{~nm}$ [27]. The maximum conversion efficiency of the optimized model is as high as of $26.15 \%$. This represents a new record value in numerical simulation of CIGS solar cells technology compared to the recently reported efforts [28-32].

\section{Conclusions}

An analytical model was used to simulate CIGS-based thin film solar cells. From the simulation results, it is found that the contribution of the space charge region in the photocurrent density is dominant compared to those of the neutral regions. However, the increases of the buffer layer thickness only reduce the cell performance at lower doping levels. In contrast, the optimum thickness of the absorber layer is around $1500-2500 \mathrm{~nm}$ from which the efficiency has not a significant increase. On the other hand, the increase of the absorber bandgap reduces the optical absorption, which is summarized in the reduction of the photocurrent density, while the open circuit voltage increases. The compromise between these effects is a bandgap of $1.15 \mathrm{eV}$ that results in maximum conversion efficiency of about $26.15 \%$. The obtained optimized efficiency is better than those that have been reported so far. These findings are very promising 
and provide a helpful guidance for future thin and high performance CIGS solar cells.

\section{Acknowledgment}

We gratefully thank Marc Burgelman and his colleagues at the University of Gent, Belgium, for providing SCAPS-1D software package for all numerical simulations reported in this paper.

\section{References}

[1] Ullal HS, Zweibel K, Roedern BV. Current status of polycrystalline thin-film PV technologies. In: Proc. of 26th IEEE Specialists Conference IEEE, 1997: 301. New York

[2] Huang C. Effects of $\mathrm{Ga}$ content on $\mathrm{Cu}$ (In, Ga) Se2 solar cells studied by numerical modeling. Journal of Physics and Chemistry of Solids, 2008; 69(2-3): 330-334.

[3] Jackson P, Hariskos D, Lotter E, Paetel S, Wuerz R, Menner R, Wischmann W, Powalla M. New world record efficiency for $\mathrm{Cu}(\mathrm{In}, \mathrm{Ga}) \mathrm{Se} 2$ thin-film solar cells beyond 20\%. Progress in Photovoltaics: Research and Applications, 2011;19(7): 894-897.

[4] Wallin E, Malm U, Jarmar T, Edoff OLM, Stolt L. World-record Cu(In,Ga)Se2-based thin-film sub-module with 17.4\% efficiency. Progress in Photovoltaics: Research and Applications, 2012; 20(7): 851-854.

[5] Agranovich V, Taylor D. Thin Films and Nanostructures. Published by Elsevier Ltd (2010); Chap 8, pp. 505-679.

[6] Shafarman WN, Siebentritt S, Stolt L. Cu(InGa)Se2 solar cells in: Luque A, Hegedus S. Handbook of photovoltaic science and engineering. England: John Wiley \& Sons Ltd (2003); Chap 13 p. 567-616.

[7] Archer MD, Hill R. Clean electricity from photovoltaics. Series on Photoconversion of Solar Energy, 2001; 1: 277-345, London: Imperial College Press; Chap 7.

[8] Burgelman M, Verschraegen J, Degrave S, Nollet P. Modeling thin-film PV devices. Progress in Photovoltaics: Research and Applications, 2004: 12(23):143-153.

[9] Shafarman WN, Huang RXS, Stephens SH. Conference Record of the (2006); IEEE 4th World Conference on Photovoltaic Energy Conversion, 1-2:420,

[10] Ramanathan K, Keane JC, To B, Dhere RG, Noufi R. In: Proc. of 20th European Photovoltaic Sol. Energy Conf.. Barcelona 2005: 16 Spain.

[11] Ramanathan K, Noufi R, To B, Young DL, Bhattacharya R, Contreras MA, Dhere RG, Teeter G. In: Proc. of 4th World Conference on Photovoltaic Solar Energy Conversion, 2006: 380, Hawaii.

[12] Burgelman M, Decock K, Khelifi S, Abass A. Advanced electrical simulation of thin film solar cells. Thin Solid Films, 2013; 535: 296-301.

[13] Lundberg O, Bodegard M, Malmstrom J, Stolt L. Prog. Photovoltaics, 2003: 11-77.

[14] Burgelman M, Nollet P, Degrave S. Modelling polycrystalline semiconductor solar cells, Thin Solid Films, 2000; 361-362: 527-532,

[15] R. Scheer, "Towards an electronic model for CuIn1-xGaxSe2 solar cells", Thin Solid Films, (2011); vol. 519, no. 21, pp. 7472-7475,.

[16] M. Mostefaoui, H. Mazari, S. Khelifi, A. Bouraiou and R. Dabou, "Simulation of High Efficiency CIGS Solar Cells with SCAPS-1D Software", Energy Procedia, vol. 74, pp. 736-744, 2015.

[17] Ouédraogo S, Zougmoré F, Ndjaka J. Numerical analysis of copper-indium-gallium-diselenide-based solar cells by SCAPS1D. International Journal of Photoenergy, 2013; 1-9.

[18] Saji VS, Lee SM, Lee CW. CIGS thin film solar cells by electrodeposition. Journal of the Korean Electrochemical Society, 2011; 14(2): 61-70.

[19] Gloeckler M, Sites JR. Band-gap grading in $\mathrm{Cu}(\mathrm{In}, \mathrm{Ga}) \mathrm{Se} 2$ solar cells. Journal of Physics and Chemistry of Solids; 66(11); 1891-1894.

[20] Lundberg, Edoff M, Stolt L. The effect of Ga-grading in CIGS thin film solar cells. Thin Solid Films, 2005; 480-481: 520-525.

[21] Contreras M, Egaas B, Ramanathan K, Hiltner J, Swartzlander A, Hasoon F, Noufi R. Progress toward 20\% efficiency in $\mathrm{Cu}(\mathrm{In}, \mathrm{Ga}) \mathrm{Se} 2$ polycrystalline thin - film solar cells. Progress in Photovoltaics: Research and Applications, 1999; 7(4): 311316.

[22] Saji V, Lee S, Lee C. CIGS thin film solar cells by electrodeposition, Journal of the Korean Electrochemical Society, 2011; 14 (2): 61-70.

[23] Wu M, Trampert A, Al-Zoubi T, Benyoucef M, \& Reithmaier JP. Interface structure and strain state of InAs nano-clusters embedded in silicon. Acta Materialia, 2015; 90: 133-139.

[24] Benyoucef M, et al. Nanostructured hybrid material based on highly mismatched III-V nanocrystals fully embedded in silicon." Physica Status Solidi (a)), 2013; 211(4): 817-822.

[25] Alzoubi T, Qutaish H, Al-Shawwa E, Hamzawy S. Enhanced UV-light detection based on ZnO nanowires/graphene oxide 
hybrid using cost-effective low temperature hydrothermal process. Optical Materials, 2018; 77: 226-232.

[26] Al-Fandi M, et al. A prototype ultraviolet light sensor based on $\mathrm{ZnO}$ nanoparticles/graphene oxide nanocomposite using low temperature hydrothermal method. IOP Conference Series: Materials Science and Engineering, 2015; 92: 012009.

[27] Bailie C, Christoforo M, Mailoa J, Bowring A, Unger E, Nguyen W, Burschka J, Pellet N, Lee J, Grätzel M, Noufi R, Buonassisi T, Salleo A, McGehee M, Semi-transparent perovskite solar cells for tandems with silicon and CIGS. Energy \& Environmental Science, 2015; 8(3): 956-963.

[28] Saadat M, et al., CIGS absorber layer with double grading Ga profile for highly efficient solar cells, Superlattices Microstruct. 2016; 92: 303-307.

[29] Ho J, Chang S, Ho J, Hsu W, Chiang C, Tsai S, Wang S, Lin C, Chou C, Yeh C, Wang K, Improving the performance of solar cells with novel buffer structure by the chemical bath deposition technique, Materials Science in Semiconductor Processing, 2017; 59: 29-34.

[30] Chelvanathan P, Hossain M, Amin N. Performance analysis of copper-indium-gallium-diselenide (CIGS) solar cells with various buffer layers by SCAPS. Current Applied Physics, 2010: 10(3): S387-S391.

[31] Bouloufa A, Djessas K, Zegadi A. Numerical simulation of CuInxGa1-xSe2 solar cells by AMPS-1D. Thin Solid Films, 2007; 515(15): 6285-6287.

[32] Benmir A, Aida M. Analytical modeling and simulation of CIGS Solar Cells. Energy Procedia, 2013; 36: 618-627. 